Revista Destaques Acadêmicos, Lajeado, v. 13, n. 1, 2021. ISSN 2176-3070

DOI: http://dx.doi.org/10.22410/issn.2176-3070.v13i1a2021.2855

http://www.univates.br/revistas

\title{
A INFLUÊNCIA DA INTERNET E REDES SOCIAIS NO PROCESSO DE DECISÃO DE COMPRA DOS CONSUMIDORES DE UMA CONFEITARIA DA CIDADE DE ESTRELA-RS
}

\author{
William Matheus Eckhardt ${ }^{1}$
}

\begin{abstract}
Resumo: Diante da popularização da Internet e redes sociais, nota-se diversas mudanças nos hábitos da população mundial e também alterações nos seus modos de vida, as quais as pessoas passam a investir parte significativa de seu tempo utilizando dispositivos digitais (computadores e smartphones) e navegando na Internet e redes sociais. Assim sendo, surge a necessidade das empresas se firmarem no meio eletrônico, divulgando de forma precisa seus produtos e posteriormente os comercializando através de lojas virtuais. Diante disso, esta pesquisa teve como objetivo identificar o poder de influencia da internet e das redes sociais e o seu impacto na decisão de compra de um produto, o qual foi lançado exclusivamente por meio das redes sociais da empresa. O estudo foi realizado através de uma pesquisa descritiva, a qual teve abordagem quantitativa, com 10 respondentes, identificados como os principais consumidores da empresa. Após a coleta dos dados, estes foram tabulados e analisados por meio de planilhas eletrônicas do programa Microsoft Excel. Ao final do estudo, conclui-se que os resultados obtidos foram importantes, entre eles estão a identificação e a comparação dos principais fatores de influência na hora da compra de um produto. Com isso, o estudo deverá auxiliar o trabalho desenvolvido nos setores de marketing das empresas da região, bem como nos processos de tomada de decisão para futuras ações comerciais das empresas.
\end{abstract}

Palavras-chave: Consumidores. Decisão de compra. Influência. Internet. Redes sociais.

\section{INTRODUÇÃO}

Tendo em vista o nítido crescimento do uso da internet e das redes sociais por grande parte da população mundial, torna-se importante identificar e analisar o poder de impacto destes canais de comunicação para o meio empresarial. Segundo Adolpho (2011), são mecanismos de interação e comunicação que podem possibilitar o fortalecimento de relacionamentos

1 Graduado do Curso de Administração de Empresas, da Universidade do Vale do Taquari UNIVATES, Lajeado/RS. Gerente Comercial. E-mail: wme.william@gmail.com. 
empresariais e pessoais, favorecem diretamente o surgimento de novas ferramentas de comercialização de produtos via internet. Desta forma, as empresas devem estar amparadas de estudos que facilitem suas tomadas de decisões ao lançar um novo produto ou serviço no mercado, colaborando por exemplo, na análise de como é composto e o que determina o processo de decisão de compra por parte dos consumidores da empresa.

Diante disso, o presente estudo tem como objetivo principal, identificar e analisar o processo de decisão de compra dos consumidores, para facilitar futuras ações de marketing das empresas e consequetemente, aumento das vendas e das receitas. Para atingir o objetivo geral do estudo e responder o problema de pesquisa definido, foram elaborados os seguintes objetivos específicos: (i) identificar o perfil dos respondentes; (ii) identificar e analisar os principais meios de comunicação utilizados pelos clientes; (iii) identificar e analisar os fatores de influência no poder de decisão de compra dos clientes. Para direcionar a pesquisa, foi elaborado um questionário (apêndice $\mathrm{A}$ ), com base na literatura referente ao tema deste estudo.

A importância do estudo deste caso, dá-se ao momento de incertezas no cenário ecônomico do país para o lançamento de uma nova linha de produtos e com isso, procurar compreeder melhor como os clientes da empresa são impactados por lançamentos de produtos e serviços por meio da Internet e redes sociais. Assim, após esta introdução, é abordada a revisão teórica sobre marketing digital e o comportamento do consumidor atual, seguida dos procedimentos metodológicos, da apresentação e análise dos resultados, da conclusão e das referências bibliográficas.

\section{FUNDAMENTAÇÃO TEÓRICA}

Com a finalidade de apresentar um embasamento científico para este estudo, apresenta-se no referencial teórico alguns conceitos e discussões sobre marketing digital e comportamento do consumidor.

Ao abordarmos o tema marketing, destaca-se o posicionamento de Kotler (2010) de que marketing "é a ciência e a arte de explorar, criar e entregar valor para satisfazer as necessidades de um mercado-alvo com lucro, identificando necessidades e desejos não realizados. Ele define, mede e quantifica o tamanho do mercado identificado e o potencial de lucro".

\subsection{Marketing Digital}

Segundo Queiroz de Azevedo e Ferreira Júnior (2015, p. 43) “marketing significa em entender e atender as necessidades do consumidor; é o mercado efetivamente em movimento, em ação". Diante das mudanças sociais e de mercado vivenciadas nos últimos anos, surge o marketing digital e com ele, surgem novas formas das empresas se comportarem e comunicarem perante $o$ mercado e seus consumidores. 
Com os avanços da Internet e das redes sociais, os consumidores têm acesso a informação de forma facilitada sobre determinados produtos e serviços oferecidos no mercado e com isso, para Adolpho (2011, p. 300) "o marketing digital se torna uma estratégia e o virtual se aproxima da realidade das empresas".

Para Kotler (2017), diante da era do Marketing 4.0, o marketing digital não vem para substituir o marketing tradicional e sim para estarem aliados, com papéis permutáveis no caminho até o consumidor e ambos oferecem ferramentas importantes com o objetivo de conquistar a defesa de marca pelos clientes.

Em determinados casos, nota-se que a utilização do marketing digital com base em uma estratégia bem planejada, possibilita atrair e conquistar novos consumidores, o que para Turban e King (2004) "a comercialização de produtos por meios eletrônicos gera uma série de benefícios para as empresas, como a redução significativa de custos, a interatividade com os clientes, a expansão da organização no mercado e a melhora nos processos organizacionais".

Diante de um cenário econômico cada vez mais concorrido, percebese que a utilização da Internet e das redes sociais surgiram nos últimos como aliadas das ações de marketing das organizações e quando bem planejadas de acordo com os objetivos das organizações, devem alcançar um número cada vez maior de pessoas e os resultados obtidos tornem-se ainda maiores no mercado.

\subsection{Comportamento do consumidor atual}

Para as organizações atingirem seus objetivos de vendas, sabe-se que é necessário conhecer e procurar entender o seu público-alvo, o qual pode exigir constantes adequações das empresas diante das exigências do seu mercado consumidor. Autores como Honorato (2004) acredita que "analisar o comportamento do consumidor é descobrir e investigar suas ações, seus sentimentos e seus pensamentos, segundo o autor, as influências que atuam sobre os consumidores definem as suas mudanças de atitude e comportamento".

Nota-se que vivemos em um mundo atualmente muito dinâmico, com o qual as mudanças e transformações ocorridas ao longo dos anos, refletem a ponto de influenciar e modificar o modo de vida das pessoas. Torna-se cada vez mais importante para as organizações, estarem atentas nestes aspectos, o que para Kotler e Armstrong (2007) "os fatores que influenciam no comportamento dos consumidores são culturais, sociais, pessoais e psicológicos". Esses fatores estão descritos no quadro a seguir: 
Quadro 1: Fatores que influenciam o comportamento do consumidor:

\begin{tabular}{|l|l|}
\hline Fatores & Características \\
\hline Culturais & $\begin{array}{l}\text { Valores básicos, classe social, percepções, desejos e comportamentos } \\
\text { adquiridos através de processos de socialização que envolvem família, } \\
\text { amigos, subcultura (religião, nacionalidade, região geográfica). }\end{array}$ \\
\hline Sociais & $\begin{array}{l}\text { Status, família, papéis sociais, influência de pequenos grupos, grupo } \\
\text { de associação e grupo de referências. }\end{array}$ \\
\hline Pessoais & $\begin{array}{l}\text { Autoimagem, estilo de vida, personalidade, situação financeira, } \\
\text { ocupação, idade e estágio do ciclo de vida. }\end{array}$ \\
\hline Psicológicas & Motivação, atitudes, aprendizagem, percepção, experiência e crenças. \\
\hline
\end{tabular}

Fonte: Adaptado Kotler e Armstrong (2007, p. 135)

Como exposto no quadro acima, nota-se que existem vários tipos de comportamento de compra e é importante ressaltar, segundo Kotler e Armstrong (2007) "o comportamento de compra pode variar de acordo com cada tipo de produto". Portanto, torna-se nítida a importância de as organizações estarem atentas com seus produtos e serviços e se estes estão satisfazendo as necessidades e objetivos dos seus consumidores. Torna-se necessário a adoção de determinados estudos e técnicas com base no seu público-alvo para analisar e procurar entender o comportamento dos consumidores e com isso poder potencializar suas vendas.

Sabe-se que atualmente, grande parte da sociedade é influenciada pelo meio da qual é cercada e também que vários fatores podem modificar seu modo de pensar e agir e também, segundo Kotler (2017) “os consumidores se importam cada vez mais com a opinião dos outros" e compartilham suas opiniões e avaliações, definindo uma imagem compilada de determinada marca. Diante disto, segundo o mesmo autor, "a internet, sobretudo a mídia social, facilitou essa grande mudança fornecendo as plataformas e as ferramentas". Percebe-se então que o uso da Internet e das redes sociais podem ser usadas como ferramentas para as empresas atingirem determinados grupos de consumidores e obterem as avaliações e opiniões dos consumidores sobre determinada marca, o que facilitará as próximas estratégias de marketing e alavancagem de vendas.

\section{PROCEDIMENTOS METODOLÓGICOS}

Como instrumento de coleta de dados, utilizou-se um questionário (apêndice A), elaborado pelo autor do presente estudo, de acordo com os objetivos específicos do estudo. As questões do questionário foram elaboradas com base na literatura de Adolpho (2011), Queiroz de Azevedo e Ferreira Júnior 
(2015), Honorato (2004), Kotler (2017), Kotler (2010), Kotler e Armstrong (2007) e Turban e King (2004).

Segundo Malhotra (2012), para a coleta de dados, deve ser adotada uma forma clara e específica. A aplicação do questionário ocorreu de forma individual com cada respondente da pesquisa, sendo o formulário e seus objetivos apresentados na etapa inicial e em seguida, liberado para preenchimento. Caso necessário, o respondente poderia solicitar esclarecimentos sobre o questionário, o que facilitou o correto preenchimento do formulário, contribuindo para o desenvolvimento da pesquisa.

Para definir o população-alvo do presente estudo, seguiu-se a definição de Malhotra (2012, p. 271): "é a coleção de elementos ou objetos que possuem as informações procuradas pelo pesquisador" e de acordo com os objetivos do presente estudo, as informações sobre o caso foram coletadas com os dez principais clientes da empresa no período de páscoa do presente ano. Para fins de tabulação dos dados, foi utilizado o programa Microsoft Excel, porque, segundo GIL (2012), a utilização de computador para processar os dados facilita o armazenamento, a organização e a análise quando se tem um grande volume de dados.

\section{APRESENTAÇÃO E ANÁLISE DOS RESULTADOS}

Nesta seção do trabalho, apresenta-se a análise e descrição dos dados obtidos, a qual organiza, sintetiza e apresenta todas as informações que foram coletadas durante a pesquisa, verificando e apresentando em formas de gráficos os resultados obtidos e também suas respectivas interpretações.

\subsection{Caracterização da amostra}

De acordo com o proposto no planejamento da pesquisa, todas as pessoas entrevistadas são clientes da empresa que apresentaram um grande volume de compras no período da Páscoa deste ano. Foram coletadas 10 respostas nos questionários enviados para os clientes selecionados.

A primeira variável dessa pesquisa refere-se ao gênero, na qual observase de acordo com gráfico 1, que $60 \%$ dos entrevistados são do sexo feminino, enquanto que $40 \%$ são do sexo masculino. 
Gráfico 1 - Gênero (\%)

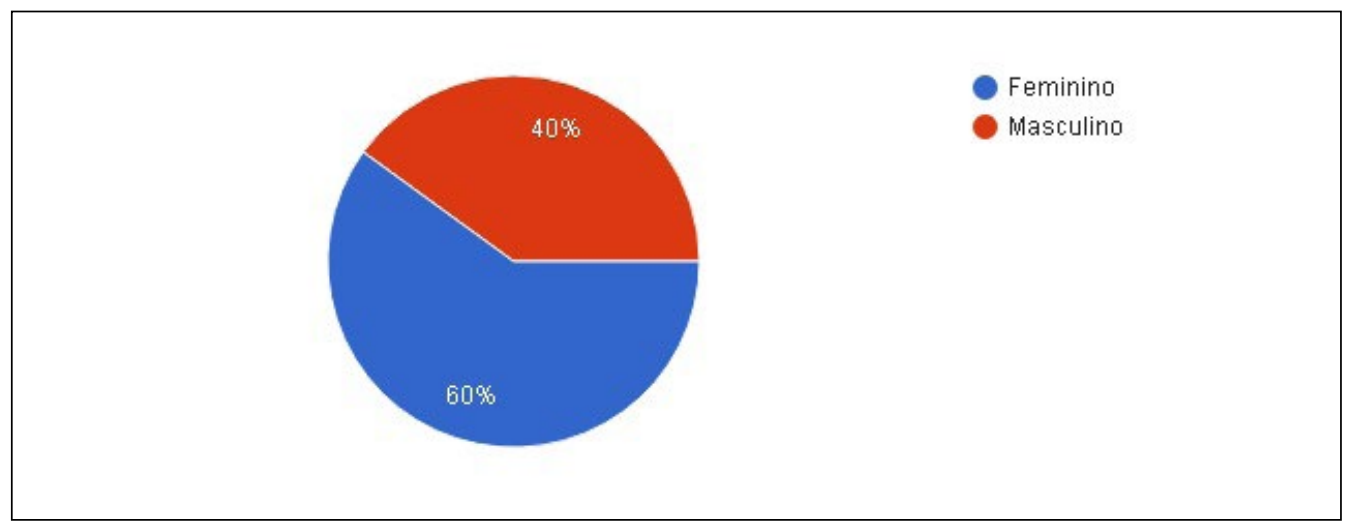

Fonte: Do autor, com base nos dados da pesquisa

Referente à a faixa etária dos participantes da pesquisa, de acordo com o gráfico 2 , observa-se que $40 \%$ dos respondentes possuem mais de 40 anos, $30 \%$ dos respondentes possuem idade entre 19 e 25 anos e $30 \%$ dos respondentes possuem idade entre 31 e 40 anos.

Gráfico 2 - Faixa etária (\%)

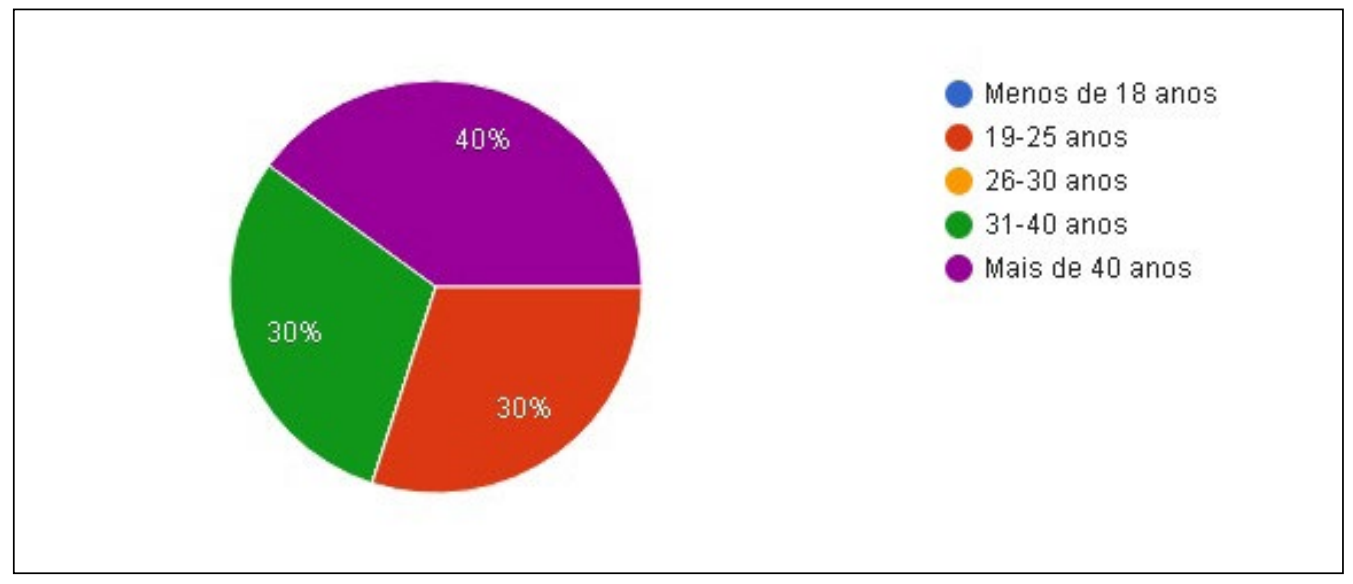

Fonte: Do autor, com base nos dados da pesquisa 


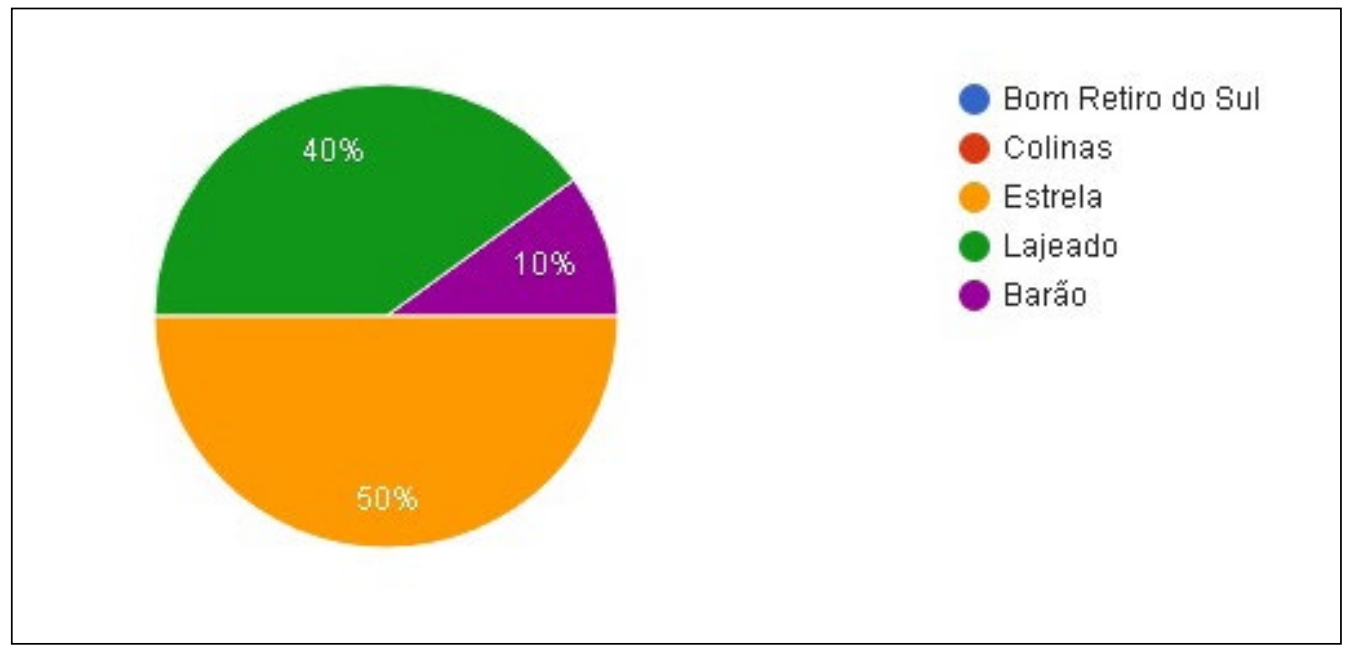

Fonte: Do autor, com base nos dados da pesquisa

Com base no gráfico 3, verifica-se que o local de residência dos entrevistados é principalmente pelas cidades do Vale do Taquari, concentrandose mais pelas cidades de Estrela (50\%), Lajeado (40\%) e Barão (10\%), pequena cidade do Vale do Caí.

Gráfico 4 - Redes Sociais (\%)

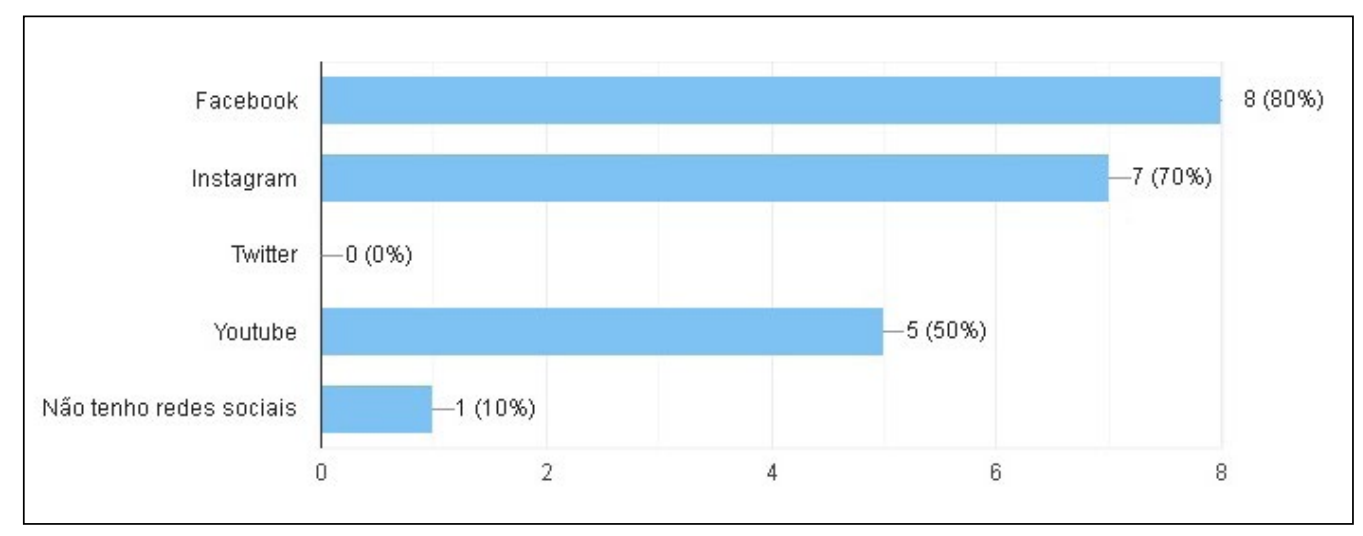

Fonte: Do autor, com base nos dados da pesquisa

Nota-se a partir do gráfico 4, que $80 \%$ dos entrevistados utilizam da rede social Facebook, sendo essa a rede social mais utilizada pelos respondentes. Em seguida, temos o Instagram com $70 \%$ dos entrevistados afirmando que utilizam, logo após, o Youtube com 50\% e, apenas $10 \%$ dos entrevistados informaram não utilizar nenhuma rede social. 
A partir do gráfico 5, observa-se que cerca de $70 \%$ dos entrevistados utilizam o computador para acessar à internet várias vezes ao dia, 10\% uma vez ao dia, 10\% afirmam utilizar alguns dias da semana e 10\% afirmam não ter acesso à internet através de um computador.

Gráfico 5 - Nível do uso do computador para acesso à internet (\%)

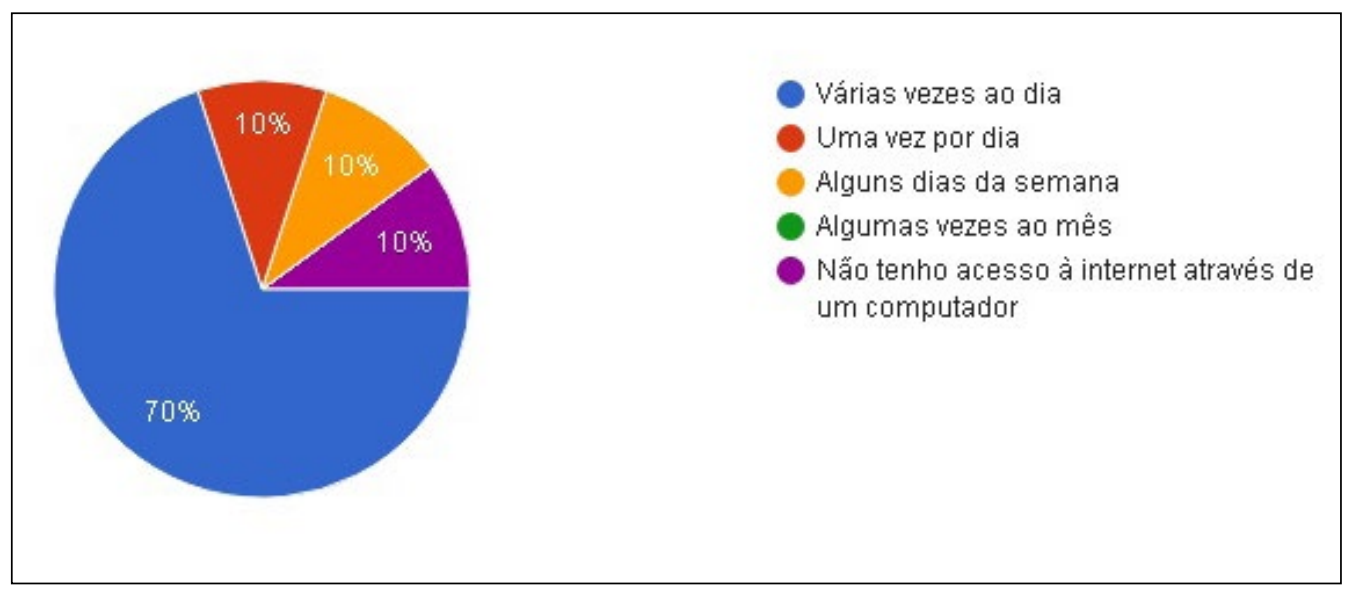

Fonte: Do autor, com base nos dados da pesquisa

Quando questionados sobre o uso do smartphone para acesso à internet durante o dia, nota-se no gráfico 6, que $100 \%$ dos respondentes utilizam o mesmo várias vezes ao dia para acesso à internet.

Gráfico 6 - Nível do uso do smartphone para acesso à internet durante o dia (\%)

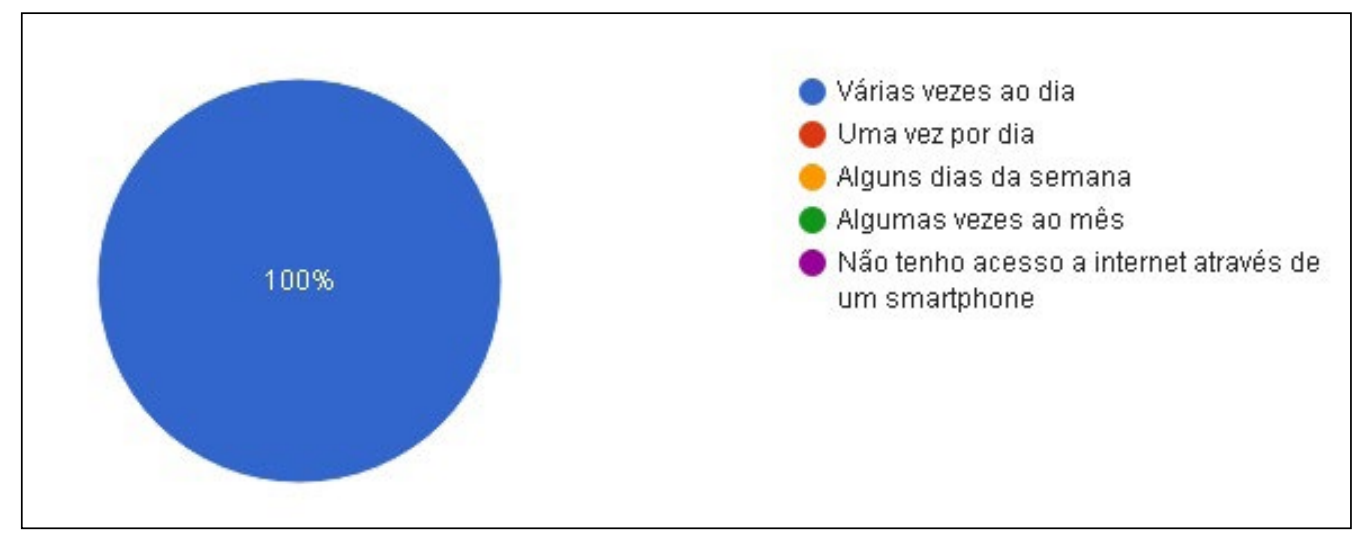

Fonte: Do autor, com base nos dados da pesquisa 
Referente ao nível de utilização de redes sociais, $90 \%$ dos entrevistados afirmam acessar suas redes sociais várias vezes ao dia, enquanto que $10 \%$ das pessoas que responderam a pesquisa não têm redes sociais.

Gráfico 7 - Nível do uso de redes sociais (\%)

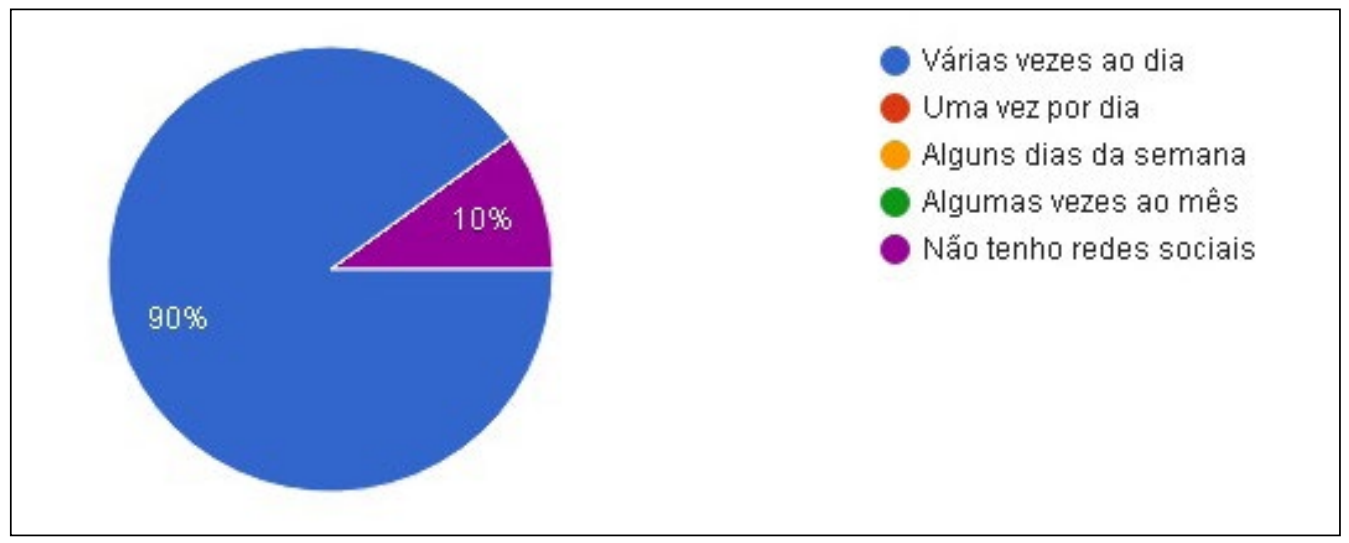

Fonte: Do autor, com base nos dados da pesquisa

É possível verificar no gráfico 8 , que $90 \%$ dos entrevistados afirmam já ter realizado a compra de um produto indicado por algum amigo nas redes sociais, enquanto somente $10 \%$ das pessoas afirmam nunca terem sido influenciadas.

Gráfico 8 - Compras realizadas por meio da influência de um amigo nas redes sociais $(\%)$

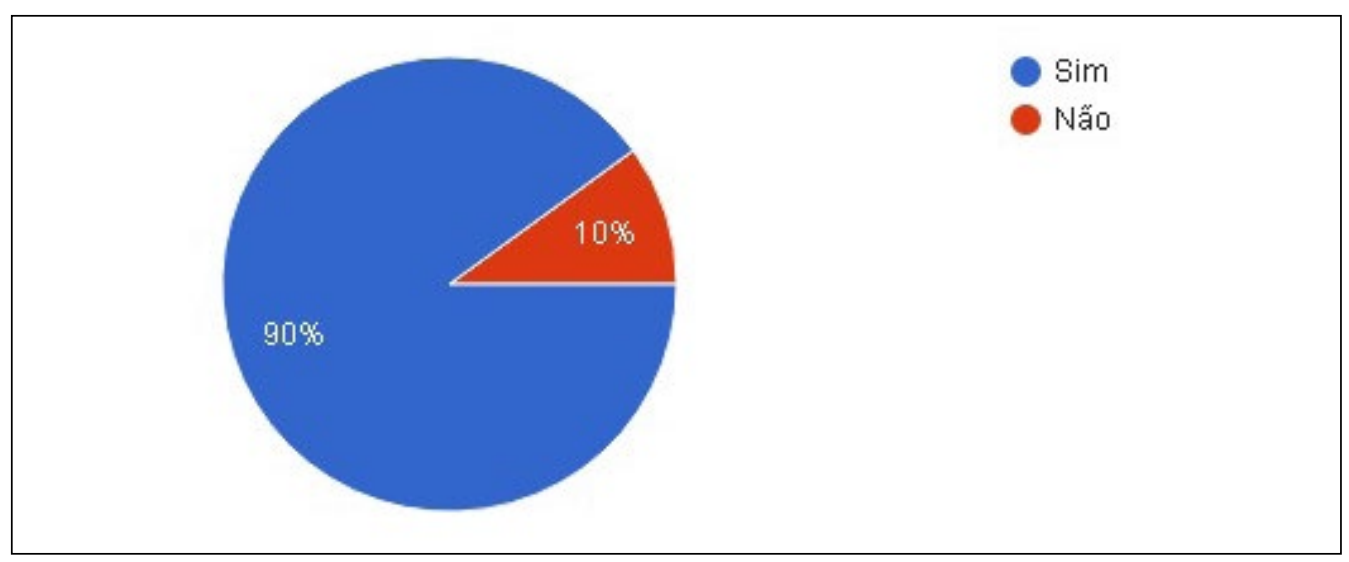

Fonte: Do autor, com base nos dados da pesquisa

No gráfico 9, nota-se que $90 \%$ dos entrevistados procuraram obter maiores informações sobre os produtos/serviços indicados por amigos. 
Somente $10 \%$ dos entrevistados já realizaram alguma compra com base somente na indicação de um amigo.

Gráfico 9 - Obtenção de informações sobre o produto/serviço indicado por um amigo (\%)

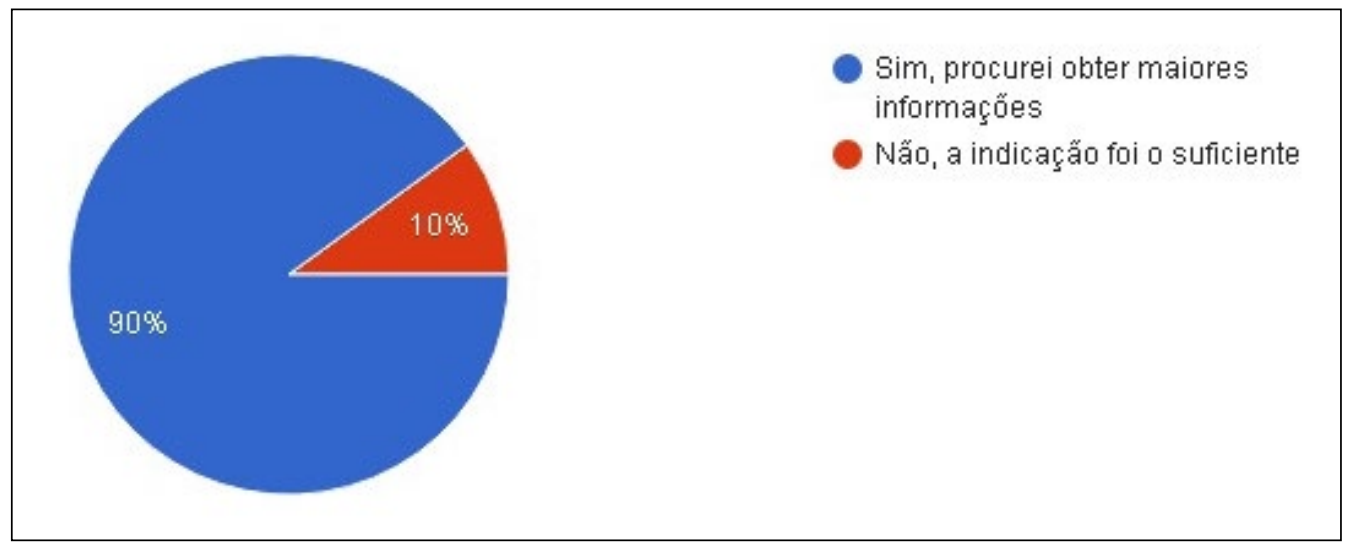

Fonte: Do autor, com base nos dados da pesquisa

Como é possível verificar no gráfico 10, 50\% dos entrevistados afirmam que a indicação de um influenciador digital (celebridade) reflete na sua decisão de compra de um produto. Enquanto que outros 50\% dos respondentes, afirmam não terem sua decisão de compra influenciada.

Gráfico 10 - Influência de um influenciador digital (celebridade) na decisão de compra $(\%)$

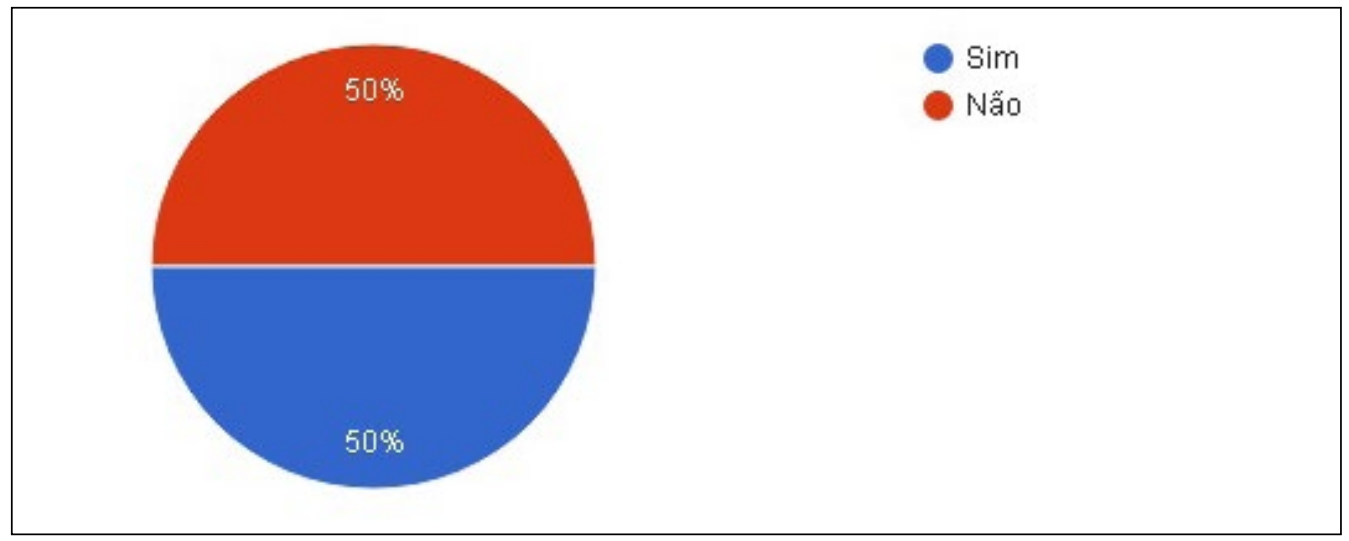

Fonte: Do autor, com base nos dados da pesquisa

Com base no gráfico 11, é possível notar que $90 \%$ dos entrevistados procuraram obter maiores informações sobre os produtos/serviços indicados 
por influenciador digital. Apenas $10 \%$ dos entrevistados afirmaram terem realizado alguma compra com base somente na indicação de um influenciador digital.

Gráfico 11 - Obtenção de informações sobre o produto/serviço indicado por um influenciador digital (\%)

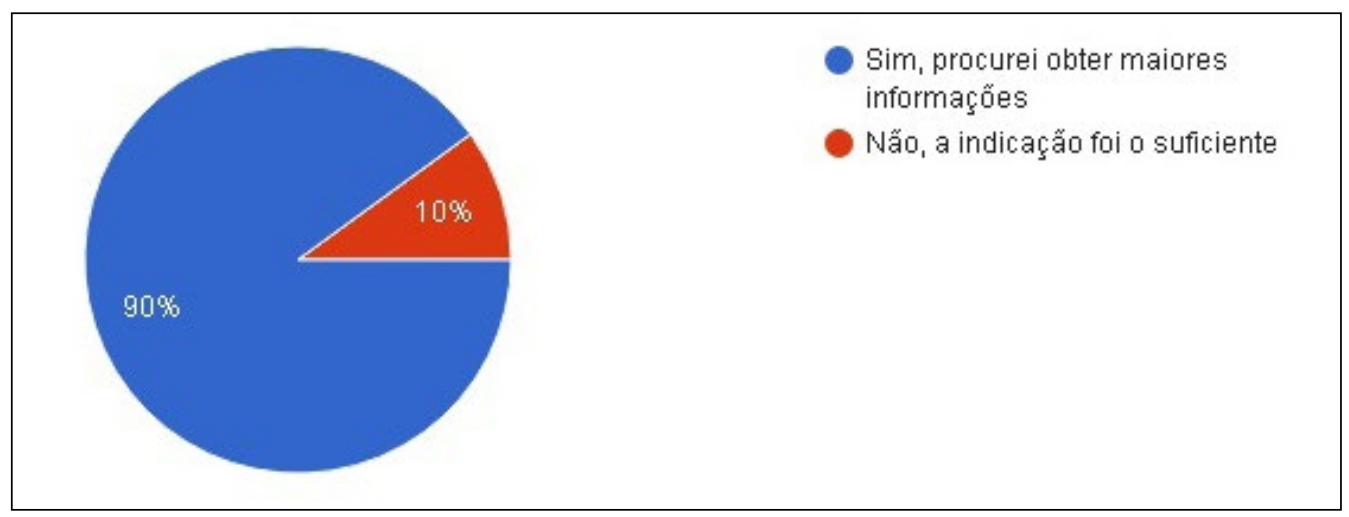

Fonte: Do autor, com base nos dados da pesquisa

No gráfico 12, nota-se que o Instagram (50\%), Facebook (40\%) e Youtube $(10 \%)$ são as redes sociais que mais influenciam os respondentes a realizar a compra de algum produto/serviço.

Gráfico 12 - Rede Social influenciadora (\%)

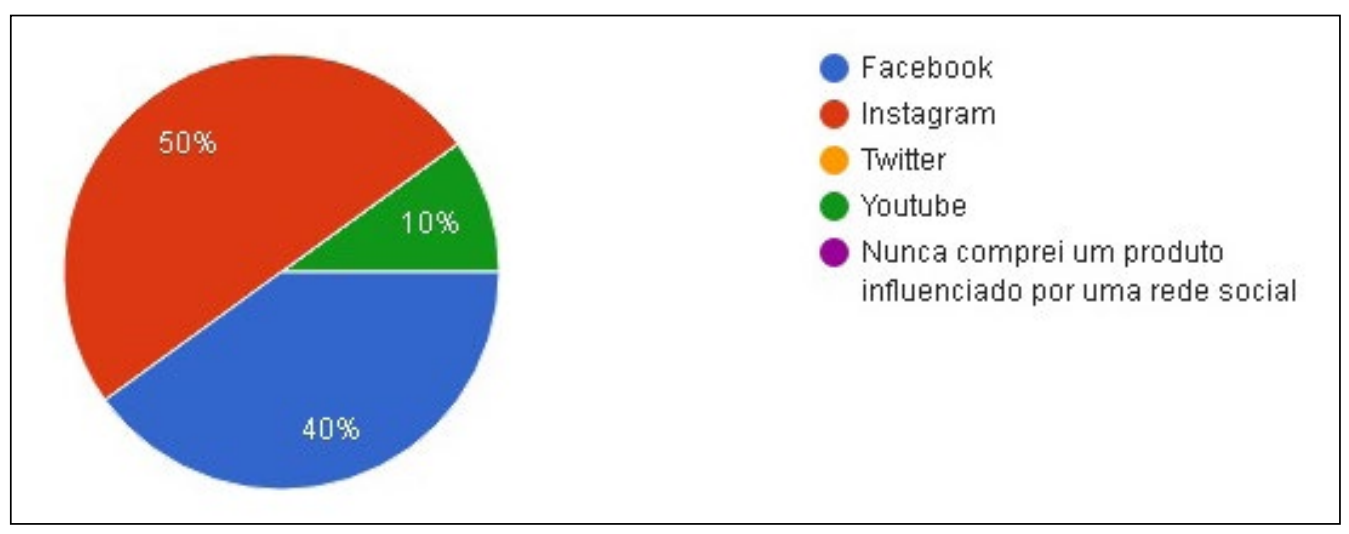

Fonte: Do autor, com base nos dados da pesquisa

No gráfico 13 , percebe-se que $70 \%$ dos entrevistados não possuem o hábito de compartilhar opiniões e avaliações sobre experiências positivas para seus amigos nas redes sociais. $20 \%$ dos entrevistados afirmaram que realizaram 
em todas experiências positivas, e apenas $10 \%$ afirmaram terem compartilhado suas opiniões e avaliações positivas apenas uma vez.

Gráfico 13 - Compartilhamento de opiniões e avaliações de experiências positivas (\%)

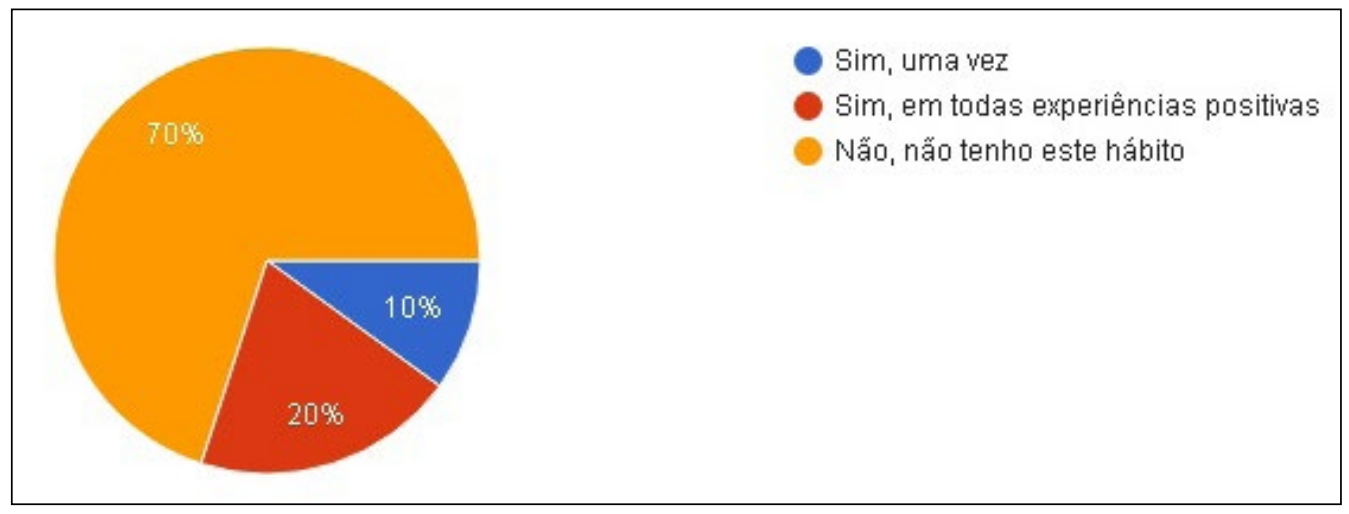

Fonte: Do autor, com base nos dados da pesquisa

Com base no gráfico 14 , nota-se que $50 \%$ dos entrevistados afirma não possuirem o hábito de compartilhar opiniões e avaliações sobre experiências negativas para seus amigos nas redes sociais, $30 \%$ dos respondentes afirmaram que realizaram em todas experiências negativas, enquanto $20 \%$ afirmam terem compartilhado suas opiniões e avaliações negativas apenas uma vez nas redes sociais.

Gráfico 14 - Compartilhamento de opiniões e avaliações de experiências negativas $(\%)$

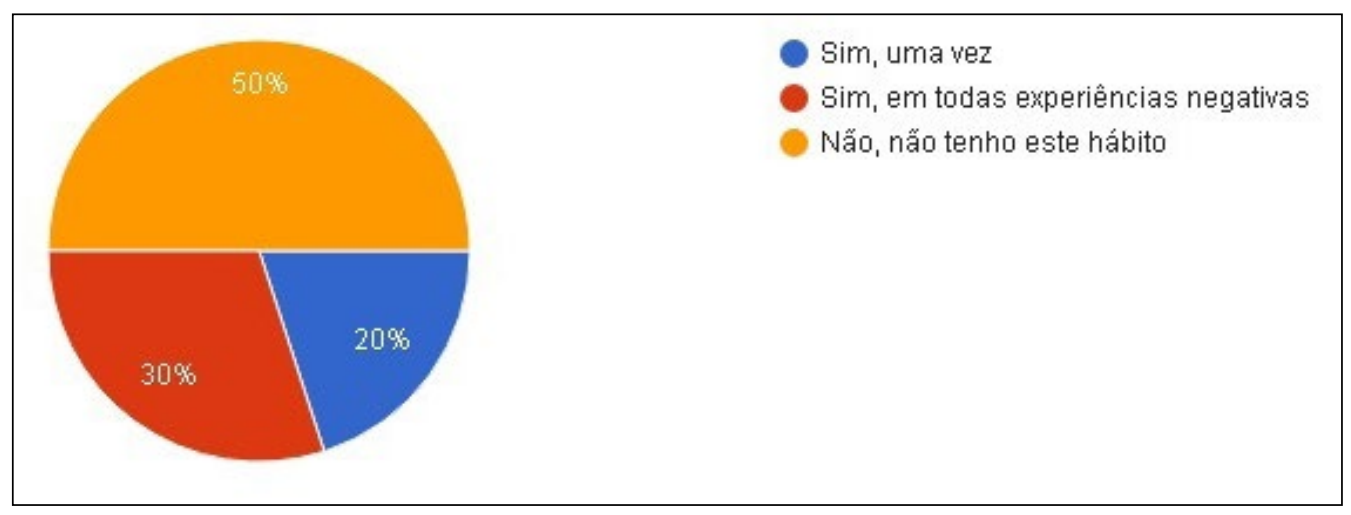

Fonte: Do autor, com base nos dados da pesquisa 


\subsection{Análise dos resultados}

Esse estudo buscou identificar qual é o papel influência das Redes Sociais e o seu impacto nas vendas de um produto e decisão de compra por parte dos clientes da empresa.

Para a aplicação dessa pesquisa, foi aplicada a técnica de amostragem não probabilística. Sobre as técnicas de amostragem, utilizou-se a amostragem por conveniência, onde o pesquisador escolhe os elementos a que possui alcance, reconhecendo que esses são capazes, de alguma maneira, de retratar o universo. Neste caso, na referente pesquisa como instrumento de coleta de dados, foram utilizados questionários, distribuídos para os dez principais clientes do período de páscoa do presente ano, e obteve-se 100\% de retorno dos respondentes.

Para Solomon (2011), o fato de procurar por bens e serviços é resultado da viabilidade e da disposição para comprar; por lado, a demanda por bens necessários tende a ser sólida no decorrer do tempo, já outros gastos podem ser adiados ou extintos caso as pessoas julgarem não ser um bom momento para investir seu dinheiro. Com base nesta colocação, nota-se que é de extrema importância as empresas estarem atentas no seu público-alvo, bem como seu poder aquisitivo e suas condições financeiras da região em que se encontram, antes de realizar alguma estratégia de marketing, bem como, um lançamento de produto. Com isso, nota-se a importância dos dados obtidos e apontados nos gráficos de 1 a 3 deste trabalho e complementados pela afirmação, dos autores Kotler e Keller (2006), que afirmam que a escolha de um produto é imensamente afetada pelas condições econômicas: débitos, economias e bens, capacidade de endividamento, renda disponível e atitude relativa a desembolsar dinheiro e economizá-lo. Segundo os mesmos autores, os padrões de consumo são moldados conforme o ciclo de vida das pessoas, relacionando-se à idade, ao sexo e ao surgimento de novas necessidades, passando por transições e transformações, mudando ao longo da vida (casamento, nascimento de filhos, doença, divórcio, mudanças na carreira, viuvez, etc.).

Os dados informados nos gráficos de 4 a 7 deste estudo, verifica-se que grande maioria dos respondentes está conectada com a Internet e Mídias sociais, o que reforça a afirmação de Kotler (2017), citada anteriormente neste trabalho, que afirma que a internet e a mídia social fornecem plataformas e ferramentas para transformações das marcas, o que permite para as empresas utilizarem esses meios como ferramentas para atingirem determinados grupos de consumidores e obterem as avaliações e opiniões dos consumidores sobre determinada marca ou produto, facilitando suas próximas estratégias comerciais.

Nos gráficos de 8 a 14, nota-se a importância de as organizações estarem atentas aos comportamentos dos clientes nas redes sociais, que como citado anteriormente neste trabalho, conforme a afirmação de Kotler (2017), 
"os consumidores se importam cada vez mais com a opinião dos outros" e compartilham suas opiniões e avaliações, definindo uma imagem compilada de determinada marca. Com base nestes gráficos, também é possível conectar com as definições das etapas do processo de compra por parte do consumidor, o que segundo Lake (2009), o "processo de tomada de decisão possui natureza psicológica e é caracterizado como um processo cognitivo. A autora complementa, afirmando que "o processo de tomada de decisão do consumidor é o mesmo em qualquer tipo de compra, seja de um produto ou serviço". Segundo a mesma autora, este processo consiste em cinco passos, que são eles: a necessidade de reconhecimento e consciência, a busca por informações, a avaliação das opções, a compra e a avaliação pós-aquisição.

\section{CONSIDERAÇÕES FINAIS}

Esse estudo buscou como objetivo principal, identificar e analisar o processo de decisão de compra dos consumidores, para facilitar futuras ações de marketing das empresas. Como primeiro objetivo específico do estudo, o pesquisador buscou identificar qual era o perfil dos respondentes. Com a análise das respostas, foi possível identificar que a maioria dos seus clientes são mulheres, na faixa dos 41 anos ou mais, residentes principalmente na cidade de Estrela-RS e Lajeado-RS. O segundo objetivo específico foi de identificar e analisar os principais meios de comunicação utilizados pelos clientes. Com a análise das respostas, foi possível identificar que a grande maioria dos respondentes utiliza o computador e o smartphone para acessar a internet várias vezes ao dia, bem como o acesso em redes sociais, destacando o Facebook como principal rede social, seguido do Instagram. Redes sociais estas que são utilizadas por quase totalidade dos respondentes da pesquisa.

Como terceiro e último objetivo da pesquisa, o pesquisador buscou identificar e analisar os fatores de influência no poder de decisão de compra dos clientes. De acordo com a análise das respostas obtidas, nota-se que a grande maioria dos entrevistados já realizou compras por influência de amigos em redes sociais, os quais também realizam pesquisa para obter maiores informações sobre o produto, mesmo que este produto tenha sido divulgado por amigos ou algum influenciador digital (celebridade). Quando questionados qual a rede social que possui maior influência para compra de determinado produto/ serviço, o Instagram foi a rede social mais citada, seguido do Facebook.

Ao término deste estudo, considerando que o objetivo geral da pesquisa foi respondido por meio da apresentação dos resultados, pode-se afirmar que a conclusão do estudo foi satisfatória, porque apresentou informações relevantes que permitem que os profissionais da área de marketing, bem como gestores de empresas da região do Vale do Taquari, principalmente das cidades de Estrela e Lajeado, possam usufruir dos resultados obtidos para embasarem suas estratégias e ações de marketing e planejamento comercial, sejam eles de nível municipal, regional ou até mesmo estadual. Essas ações podem resultar 
em aumento de conhecimento da sua marca, resultando no aumento de público para venda dos seus produtos ou serviços e consequentemente, aumento das receitas das empresas.

Para o responsável pelo estudo, a pesquisa oportunizou a aquisição de maior conhecimento nas áreas de marketing e vendas, bem como acréscimos de competências. Além disso, possibilitou a implantação prática de conceitos estudados ao longo da sua formação acadêmica e posterior apresentação e aplicação dos resultados do estudo para a empresa na qual ocupa o cargo de gerente.

\section{REFERÊNCIAS}

ADOLPHO, C. Os 8 Ps do Marketing Digital: O Seu Guia Estratégico de Marketing Digital. São Paulo: Novatec, 2011.

FERREIRA JÚNIOR, A. B.; AZEVEDO, N. Q. Marketing Digital: Uma análise do mercado 3.0. Curitiba: Editora Intersaberes, 2015.

GIL, A. C. Métodos e técnicas de pesquisa social. 6. ed. São Paulo: Atlas, 2012.

HONORATO, G. Conhecendo o marketing. 1a ed. São Paulo: Manole, 2004.

KOTLER, P.; KELLER, Kevin Lane. Administração de Marketing. 12. ed. São Paulo: Pearson Prentice Hall, 2006.

KOTLER, P. Marketing 3.0: as forças que estão definindo o novo marketing centrado no ser humano. Rio de Janeiro: Elsevier, 2010.

KOTLER, P. Marketing 4.0. Rio de Janeiro: Sextante, 2017.

KOTLER, P.; ARMSTRONG, G. Princípio de Marketing. São Paulo: Pearson Prentice Hall, 2007.

LAKE, L. Comportamento do consumidor para leigos. Rio de Janeiro: Alta Books, 2009.

MALHOTRA, N. K. Pesquisa de marketing: uma orientação aplicada. 6. ed. Porto Alegre: Bookman, 2012.

TURBAN, E.; KING, D. Comércio eletrônico: estratégia e gestão. São Paulo: Pearson Prentice Hall, 2004.

SOLOMON, Michael R. O comportamento do consumidor: comprando, possuindo e sendo. Tradução de Luiz Carlos de Queiroz Faria. 9. ed. Porto Alegre: Bookman, 2011. 


\section{APÊNDICE}

APÊNDICE A - Questionário realizado com o público-alvo.

Pesquisa - Marketing digital: $O$ impacto da utilização das redes sociais na decisão de compra

1. Qual é o seu sexo?

( ) Masculino

( ) Feminino

2. Qual é a sua faixa etária?

( ) Menos de 18 anos

( ) 19-25 anos

( ) 26-30 anos

( ) 31-40 anos

( ) Mais de 40 anos

3. Qual a cidade que você reside?

( ) Bom Retiro do Sul

( ) Colinas

( ) Estrela

( ) Lajeado

( ) Outra:

4. Quais redes sociais você possui?

( ) Facebook

( ) Instagram

( ) Twitter

( ) Youtube

( ) Não tenho redes sociais

5. Com que frequência você utiliza um computador para acessar à internet?

( ) Várias vezes ao dia

( ) Uma vez por dia

( ) Alguns dias da semana

( ) Algumas vezes ao mês

( ) Não tenho acesso à internet através de um computador 
6. Com que frequência você utiliza um smartphone para acessar à internet?

( ) Várias vezes ao dia

( ) Uma vez por dia

( ) Alguns dias da semana

( ) Algumas vezes ao mês

( ) Não tenho acesso a internet através de um smartphone

7. Com que frequência você costuma acessar as suas redes sociais?

( ) Várias vezes ao dia

( ) Uma vez por dia

( ) Alguns dias da semana

( ) Algumas vezes ao mês

( ) Não tenho redes sociais

8. Você já comprou algum produto indicado por um amigo nas redes sociais?

( ) $\mathrm{Sim}$

( ) Não

9. Você procurou obter maiores informações sobre o produto/serviço ou a indicação do seu amigo foi o suficiente?

( ) Sim, procurei obter maiores informações

( ) Não, a indicação foi o suficiente

10. Para você, a indicação de um produto ou serviço por meio de um influenciador digital (celebridade) reflete na sua decisão de compra?
( ) Sim
( ) Não

11. Você procurou obter maiores informações sobre o produto/serviço ou a indicação do influenciador digital foi o suficiente?

( ) Sim, procurei obter maiores informações

( ) Não, a indicação foi o suficiente

12. Qual a principal rede social que influencia você a conhecer e comprar novos produtos e serviços?
( ) Facebook
( ) Instagram
( ) Twitter
( ) Youtube 
( ) Nunca comprei um produto indicado por um influenciador digital

13. Você costuma compartilhar suas opiniões e avaliações de suas experiências positivas com determinado produto ou serviços para seus amigos nas redes sociais?

( ) Sim, uma vez

( ) Sim, em todas experiências positivas

( ) Não, não tenho este hábito

14. Alguma vez você já compartilhou para seus amigos nas redes sociais suas opiniões e avaliações de alguma experiência negativa com determinado produto ou serviços?

( ) Sim, uma vez

( ) Sim, em todas experiências negativas

( ) Não, não tenho este hábito 